\title{
Clinical Study of Postoperative Bleeding after Tonsillectomy in 497 Cases
}

\author{
Takeshi Tanaka ${ }^{1}$ Kenji Ishii ${ }^{1}$ Kyoko Matsumoto ${ }^{1}$ \\ Tomonobu Kamio ${ }^{1}$
}

\author{
Address for correspondence Takeshi Tanaka, MD, PhD, Department \\ of Otorhinolaryngology, Kamio Memorial Hospital, 2-25 \\ Kanda-Awaji-cho, Chiyoda Ward, Tokyo, Japan 101-0063 \\ (e-mail: wplants@mac.com).
}

\begin{abstract}
Keywords

- tonsillectomy

- postoperative bleeding

- chronic tonsillitis
\end{abstract}

\section{Introduction}

Tonsillectomy is a basic technique that otorhinolaryngologists learn during their intern stage. As it is performed often, it is considered to be a basic technique for otorhinolaryngologists. However, in an oral cavity with poor visibility and limited space, it can be difficult even for experienced surgeons to remove the palatine tonsils if they are strongly adhered. Thus, this technique should not necessarily be performed by novice surgeons. If intraoperative hemostasis is inadequate, postoperative bleeding can occur during extubation or after the patient leaves the operating room, making hemostasis challenging. In rare cases, it could result in life-threatening complications. Therefore, other medical staff as well as surgeons must exercise caution when performing tonsillectomy.

In this study, we examined cases of tonsillectomy performed at our hospital, and investigated factors associated with postoperative bleeding.

received

June 11,2020

accepted

October 9, 2020
DOI https://doi.org/

$10.1055 / \mathrm{s}-0041-1723787$. ISSN 2569-1783.

\section{Materials and Methods}

This study included 497 cases of tonsillectomy performed at our hospital during 3 years between September 2015 and August 2018. Age at the time of tonsillectomy ranged from 3 to 86 years, with a mean of 27.6 years ( - Fig. 1 ). Of the included patients, 278 were males and 219 were females; the proportion of males was slightly higher (1.3:1). The target diseases were as follows: 367 cases of chronic tonsillitis, 125 cases of tonsillar hypertrophy, 2 cases of palmoplantar pustulosis, 2 cases of immunoglobulin A nephropathy, and 1 case of nephrotic syndrome. There were no cases of neoplastic lesions. In subjects aged $<20$ years, there were many cases of tonsillar hypertrophy (76.7\%; 79 cases). However, in subjects aged $\geq 20$ years, majority of the cases were of chronic tonsillitis, which is an inflammatory disease (87.3\%; 344 cases) ( - Table 1 ). In the subjects aged $\geq 20$ years, if rhonchopathy or sleep apnea was noted, wherein tonsillar hypertrophy was

\footnotetext{
(C) 2021. The Author(s).

This is an open access article published by Thieme under the terms of the Creative Commons Attribution-NonDerivative-NonCommercial-License, permitting copying and reproduction so long as the original work is given appropriate credit. Contents may not be used for commercial purposes, or adapted, remixed, transformed or built upon. (https://creativecommons.org/ licenses/by-nc-nd/4.0/) Georg Thieme Verlag KG, Rüdigerstraße 14, 70469 Stuttgart, Germany
} 


\section{0 cases}

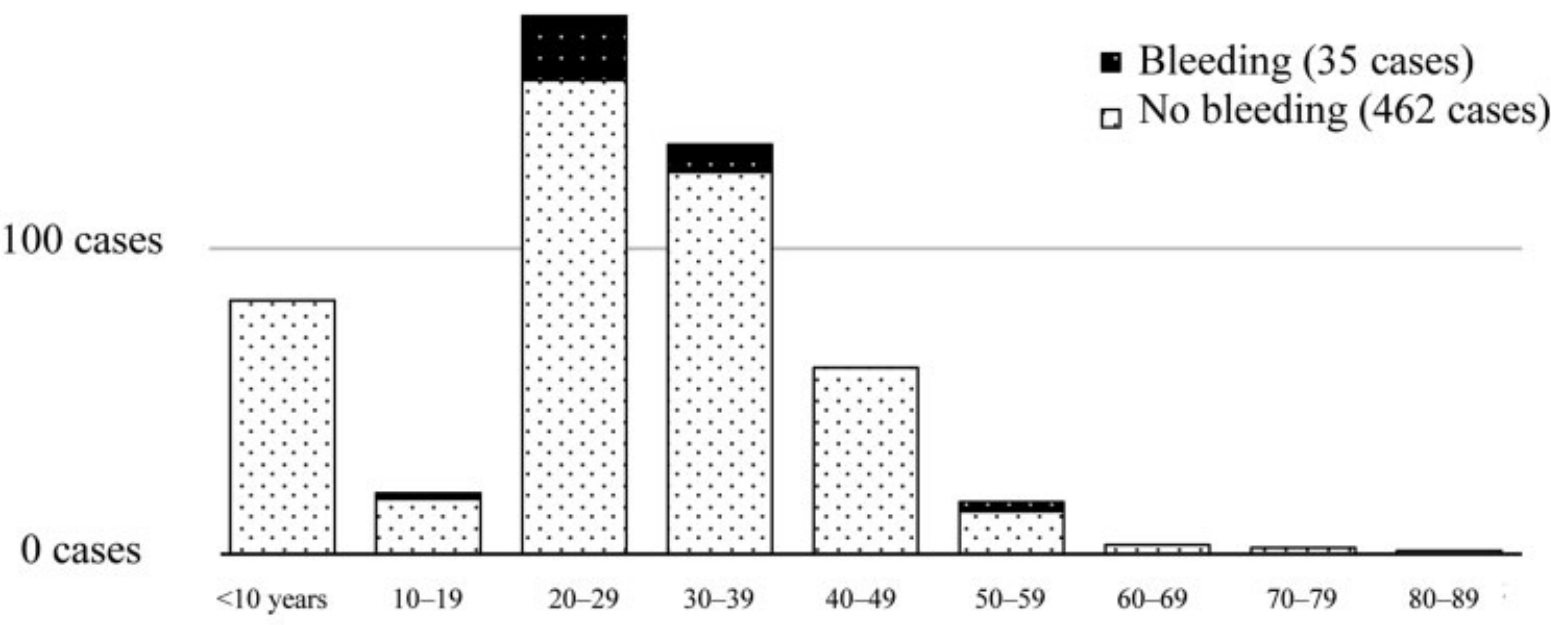

Fig. 1 Age distribution and postoperative bleeding. Many cases of postoperative bleeding were subjects in their 20s and 30s.

Table 1 Target illnesses and age distribution

\begin{tabular}{|l|l|l|l|l|}
\hline & $<\mathbf{2 0} \mathrm{y}$ & $\mathbf{2 0 - 3 9} \mathrm{y}$ & $\mathbf{2} \mathbf{4 0} \mathrm{y}$ & Total \\
\hline Chronic tonsillitis & $23(2)$ & $\mathbf{2 8 7}(30)$ & $57(2)$ & $367(34)$ \\
\hline $\begin{array}{l}\text { Tonsillar } \\
\text { hypertrophy }\end{array}$ & 79 & 21 & $25(1)$ & $125(1)$ \\
\hline $\begin{array}{l}\text { Palmoplantar } \\
\text { pustulosis }\end{array}$ & 0 & 0 & 2 & 2 \\
\hline IgA nephropathy & 0 & 2 & 0 & 2 \\
\hline $\begin{array}{l}\text { Nephrotic } \\
\text { syndrome }\end{array}$ & 1 & 0 & 0 & 1 \\
\hline Total & $103(2)$ & $310(30)$ & $84(3)$ & $497(35)$ \\
\hline
\end{tabular}

Abbreviation: IgA, immunoglobulin A.

Note: The numbers shown in parentheses "()" indicate the number of cases with postoperative bleeding.

the likely cause (11.7\%; 46 cases), palatoplasty was performed in addition to tonsillectomy, if necessary.

All operations were performed under general anesthesia. After injecting $1 \%$ lidocaine with epinephrine around the tonsils as a local anesthetic and incising the mucous membrane, the capsule of the superior pole of the tonsillar was confirmed. Subsequently, swabs and forceps were used to bluntly resect along the tonsillar capsule toward the inferior pole of the tonsillar. If there were any adhesions or blood vessels, the part cauterized by the bipolar electrode was resected. Caution should be exercised so as to not enter the muscular layer. When the resection was completed at the inferior pole, the tonsillar bed was ligated with a 2-0 silk thread to resect the palatine tonsils.

Postoperatively, subjects were administered antibacterial agents intravenously for 3 days. It was not followed by oral antibiotic. As pain management, oral administration of celecoxib was initiated on the day of operation, and loxoprofen and acetaminophen were used when necessary. If the course was favorable, subjects were discharged after 7 days postoperatively.
Table 2 Comparison of risk factors for postoperative bleeding

\begin{tabular}{|l|l|l|l|}
\hline \multicolumn{2}{|l|}{ Factors } & $\begin{array}{l}\text { No bleeding } \\
\text { (462 cases) }\end{array}$ & $\begin{array}{l}\text { Bleeding } \\
\text { (35 cases) }\end{array}$ \\
\hline \multirow{3}{*}{ Sex } & Male & 248 & 30 \\
\cline { 2 - 4 } & Female & 214 & 5 \\
\hline $\begin{array}{l}\text { Operation } \\
\text { duration }\end{array}$ & $\begin{array}{l}\text { Mean } \\
\text { (min) }\end{array}$ & 55 & 61 \\
\hline $\begin{array}{l}\text { Body mass } \\
\text { index }\end{array}$ & $\begin{array}{l}\text { Mean } \\
\left(\mathrm{kg} / \mathrm{m}^{2}\right)\end{array}$ & 21.5 & 20.9 \\
\hline Smoking & Yes & 78 & 5 \\
\cline { 2 - 4 } & No & 384 & 30 \\
\hline \multirow{3}{*}{ Hypertension } & Yes & 13 & 2 \\
\cline { 2 - 4 } & No & 449 & 33 \\
\hline Age & Mean & $27.4 \mathrm{y}$ & $29.1 \mathrm{y}$ \\
\cline { 2 - 4 } & $<20 \mathrm{y}$ & 101 & 2 \\
\cline { 2 - 4 } & $20-39 \mathrm{y}$ & 280 & 30 \\
\cline { 2 - 4 } & $\geq 40 \mathrm{y}$ & 81 & 3 \\
\hline
\end{tabular}

In this study, postoperative bleeding was defined as confirmed bleeding or clot during an examination by a physician, which was recorded in the patients' medical records. Cases where bleeding was only reported by patients or nurses and the findings could not be confirmed were not included.

We also examined the presence or absence of bleeding in subjects, sex, operation duration, body mass index (BMI), smoking, the presence or absence of hypertension, and age distribution (-Table 2 ).

To identify the patients' background factors associated with postoperative bleeding, we used postoperative bleeding (yes $=1$ and no $=0)$ as a dependent variable, and $\operatorname{sex}(\operatorname{men}=1$ and women $=0$ ), smoking (yes $=1$ and no $=0$ ), hypertension (yes $=1$ and no $=0)$, age $(<20=1,20$ to $<40=2, \geq 40=3$ ), BMI $\left(\mathrm{kg} / \mathrm{m}^{2}\right.$; continuous variable), and operation duration 
10 cases

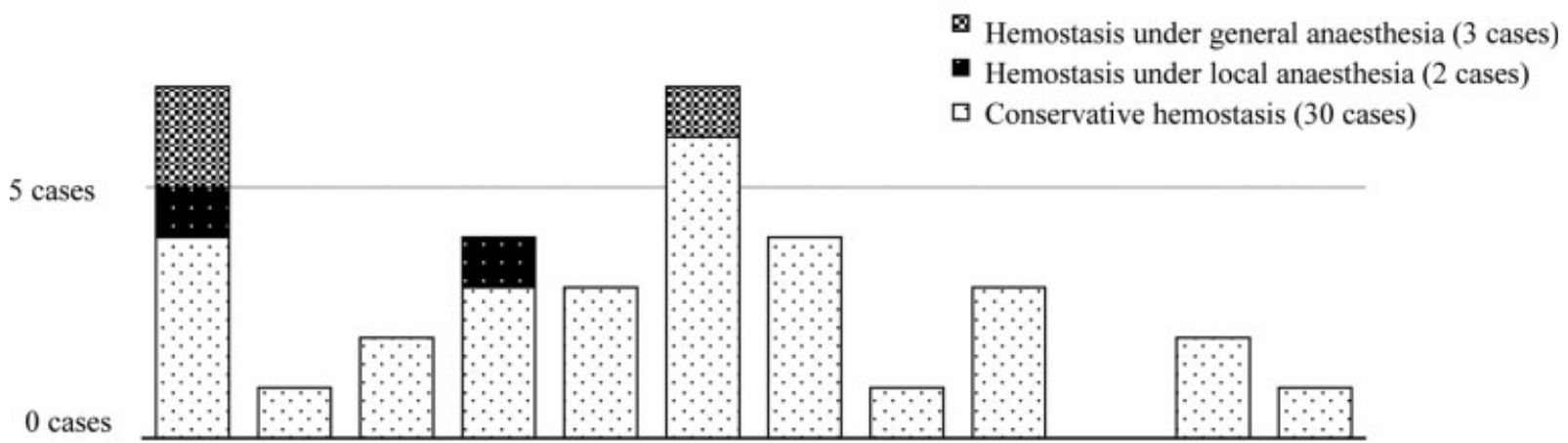

Within 24 hrs day 2 day 3 day 4 day 5 day 6 day 7 day 8 day 9 day 10 day 11 day 12

Fig. 2 Timing of postoperative bleeding and method of hemostasis. Majority of the cases of postoperative bleeding were within 24 hours and on day 6 .

(minutes; continuous variable) as explanatory variables to obtain odds ratio (OR) and 95\% confidence interval (CI) through binominal logistic regression analysis (forced entry). Statistical analysis was performed using SPSS version 22 for Windows with a significance level $<0.05$. For cases where adenoidectomy, ear tube insertion, soft palatoplasty, etc. were performed simultaneously, the operation duration included the time required for completion of all the procedures.

This study was approved by the ethics committee of Kamio Memorial Hospital (receipt number 5; August 13, 2020).

\section{Results}

Among 497 cases of tonsillectomy, postoperative bleeding occurred in 35 cases (7.0\%). According to age, postoperative bleeding occurred in 21 cases in their 20s and 9 cases in their 30s; $85.7 \%$ of the total cases were within these two groups (-Fig. 1). Considering the method of hemostasis, conservative hemostasis was used for 30 cases, hemostasis under local anesthesia was used for two cases, and hemostasis under general anesthesia was used for three cases. Postoperative bleeding was most often identified within 24 hours postoperatively and 6 days postoperatively. However, seven cases (20\%) developed bleeding again after discharge and required rehospitalization. The longest case developed bleeding 12 days after being discharged (- Fig. 2).
We compared postoperative bleeding according to risk factors, wherein binomial logistic regression analysis revealed significant differences in sex $(p<0.001)$ and age $(p=0.021)$ (-Table 3). Males had the highest risk of postoperative bleeding, with an OR of 7.35 (95\% CI: 2.66-20.3), as compared with females. The risk OR for postoperative bleeding by age was $0.02(1.14-5.23)$. The incidence for ages 20 to 39 years was $10.7 \%$, which was higher than that for $<20$ years $(2.0 \%)$ and $>40$ years $(3.7 \%)$. No statistically significant differences were observed for operation duration, BMI, smoking, or hypertension.

\section{Discussion}

The incidence of postoperative bleeding following tonsillectomy ranged from 1 to $20 \%,{ }^{1-7}$ which is likely caused by the difference in the definition of postoperative bleeding. In this study, we defined the presence of clot and fresh bleeding in the medical records as postoperative bleeding, which required direct examination by a physician and some form of treatment, such as antihemorrhagic agent intravenous (IV) drip or hemostasis treatment. Thus, minor bleeding that did not cause any clinical issues was not included. Among 35 cases $(7.0 \%)$ of postoperative bleeding, three $(0.6 \%)$ required hemostasis under general anesthesia, which was somewhat lower than that indicated in other reports. ${ }^{1-7}$

Table 3 Binominal logistic analysis of patient factors that impact postoperative bleeding

\begin{tabular}{|l|l|l|l|l|}
\hline & $\begin{array}{l}\text { Partial correlation } \\
\text { coefficient }\end{array}$ & Odds ratio & $\begin{array}{l}\text { 95\% confidence interval } \\
\text { (lower limit-upper limit) }\end{array}$ & $p$-Value \\
\hline Sex & 1.99 & 7.34 & $2.66-20.3$ & $<0.001$ \\
\hline Operation duration & 0.006 & 1.01 & $0.99-1.02$ & 0.342 \\
\hline Body mass index & -0.097 & 0.91 & $0.81-1.02$ & 0.098 \\
\hline Smoking & -0.962 & 0.38 & $0.13-1.11$ & 0.077 \\
\hline Hypertension & 0.33 & 1.4 & $0.25-7.69$ & 0.703 \\
\hline Age & 0.896 & 2.45 & $1.15-5.23$ & 0.021 \\
\hline
\end{tabular}


Timing of postoperative bleeding was early ( 24 hours postoperatively) and late ( 6 days postoperatively), similar to other reports $^{1-4,6,7}$ (- Fig. 2). Early bleeding is likely caused by inadequate intraoperative hemostasis ${ }^{4}$ and promoted by cough reflex during extubation or postoperative coughing. Immediately after an operation, pain and anxiety tend to elevate blood pressure, making the incision unstable; thus, bleeding makes hemostasis treatment difficult, at times requiring another operation under general anesthesia. ${ }^{1}$ Therefore, if hemostasis cannot be achieved using conservative treatment immediately after the operation, palatoglossal arch and palatopharyngeal arch are immediately sutured under local anesthesia to achieve hemostasis.

Late bleeding observed between 4 and 7 days postoperatively often develops when scabs on the tonsillar fossa peel as the incision heals. As compared with early bleeding, late bleeding tends to form clots, wherein the degree of bleeding is mild, and can often be managed conservatively, with an antihemorrhagic agent IV drip. There were seven cases of postdischarge bleeding, with the longest duration being 12 days postoperatively; thus, it is important to provide meal and lifestyle guidance for 2 weeks postoperatively.

Risk factors for postoperative bleeding include being a male, operation duration, smoking, use of antibacterial agents, and inflammatory diseases. ${ }^{1-7}$ In this study, risk factors for postoperative bleeding were being a male and being aged between 20 and 39 years. Other studies have discussed postoperative bleeding in males, ${ }^{2,3,6}$ but the present study is characterized by having many cases of bleeding in the younger population. This was likely because $92.6 \%$ of the subjects aged 20 to 39 years underwent an operation to treat chronic tonsillitis ( - Table $\mathbf{1}$ ), indicating a higher rate of chronic tonsillitis in this group compared with the other groups. Chronic tonsillitis tends to cause growth of new vessels and adhesion with the surrounding tissues through recurring inflammation. Thus, compared with tonsillar hypertrophy, which is a noninflammatory disease, it is often difficult to remove the tonsils and achieve hemostasis in cases of chronic tonsillitis. ${ }^{1,4}$ In young individuals, peritonsillar abscess is common. ${ }^{8-10}$ Scarring of areas surrounding the tonsils and vulnerable tissues causes difficulty in removing the tonsils and achieving hemostasis during surgery. Among the present cases, 15 were treated at our hospital for peritonsillar abscess (aged 20-56 years), of which 13 (86.7\%) were aged 20 to 39 years. Postoperative bleeding was common in this age group as the ratio of inflammatory diseases was high.

Based on empirical findings, authors assumed that middleaged obese men with a smoking history would be prone to bleeding, but the present study revealed no correlation with body weight and smoking. In fact, younger males were more prone to bleeding. Although obesity was not a risk factor for postoperative bleeding in the present study, the oral cavity of obese patients typically has poor visibility, making surgery and hemostasis treatment difficult. ${ }^{4}$ Additionally, intubating obese patients is difficult and complications are likely. ${ }^{11}$ Thus, it is crucial to perform hemostasis properly to prevent additional surgery and postoperative bleeding.

As the present study showed that young males are prone to postoperative bleeding, the risk of postoperative bleeding must be emphasized when providing explanations to such patients. Since postoperative bleeding can occur before as well as after discharge, the possibility of extended hospitalization and rehospitalization must be discussed. Although postoperative bleeding is less likely for minors, the burden on the accompanying family members is high; however, 7-day postoperative hospitalization is not always necessary and early discharge can be considered.

\section{Conclusion}

We examined 497 cases of tonsillectomy performed at our hospital over a 3-year period. Postoperative bleeding was confirmed in 35 cases (7.0\%), of which three cases $(0.6 \%)$ required additional surgery under general anesthesia. Postoperative bleeding was often found 24 hours postoperatively and 6 days postoperatively. Risk factors for postoperative bleeding were being a male and being aged between 20 and 39 years.

\section{Conflicts of Interest}

None declared.

\section{Acknowledgment}

We would like to extend our sincere appreciation to Dr. Yasutaka Aihara of Clinica Kanda and Dr. Masahiko Sumitani of Department of Pain and Palliative Medicine/ Anesthesiology and Pain Relief Center, The University of Tokyo Hospital.

\section{References}

1 Marusasa N, Iwai H, Yoshinaga K, et al. Postoperative hemorrhage after tonsillectomy. J Japanese Stomatolog Soc 2001;13:237-241

2 Mitsuhashi Y, Sasaki A, Takeda I, et al. Postoperative hemorrhage after tonsillectomy. J Japanese Stomatolog Soc 2017;30:129-133

3 Okada M, Kobayashi T, Nakamura K. Postoperative hemorrhage after tonsillectomy. Practica Oto-Rhino-Laryngologica 2009;102; 219-223

4 Ishida R, Nakamura S, Fuke T, Yamada H. Postoperative hemorrhage after tonsillectomy. Practica Oto-Rhino-Laryngologica 2006; 99:391-395

5 Fonseca ACG, Engelhardt MI, Huang ZJ, Jiang ZY, Yuksel S, Roy S. Effect of changing postoperative pain management on bleeding rates in tonsillectomy patients. Am J Otolaryngol 2018;39(04): 445-447

6 Chujo K, Hiraya Y, Takahashi M, et al. Cases of hemorrhage after tonsillectomy at our department. Oto-Rhino-Laryngology 2017; 60:17-22

7 Ikenaga M, Kumagami H. The relationship between postoperative hemorrhage after tonsillectomy and smoking. J Japan Soc Head Neck Surg 2019;29:27-30

8 Rokkjaer MS, Klug TE. Tonsillar malignancy in adult patients with peritonsillar abscess: retrospective study of 275 patients and review of the literature. Eur Arch Otorhinolaryngol 2015;272 (09):2439-2444

9 Kanebayashi H, Ogawa Y, Yamanishi T, et al. Clinical examination of peritonsillar abscess. Oto-Rhino-Laryngology 2003;46:284-288

10 Umibe A, Anazawa U, Kessoku H, et al. Clinical examination of 115 cases of peritonsillar abscess. Nippon Jibiinkoka Gakkai Kaiho 2015;118(10):1220-1225

11 De Jong A, Molinari N, Pouzeratte Y, et al. Difficult intubation in obese patients: incidence, risk factors, and complications in the operating theatre and in intensive care units. Br J Anaesth 2015; 114(02):297-306 